\title{
Extended Temperature Solar Cell Technology Development
}

\author{
Geoffrey A. Landis* \\ NASA Glenn Research Center, Cleveland, OH 44135 \\ Phillip Jenkins and David Scheiman $\dagger$ \\ The Ohio Aerospace Institute, Cleveland, $\mathrm{OH} 44135$ \\ Ryne Rafaelle ${ }^{* *}$ \\ Rochester Institute of Technology, Rochester NY 14623
}

\begin{abstract}
Future NASA missions will require solar cells to operate both in regimes closer to the sun, and farther from the sun, where the operating temperatures will be higher and lower than standard operational conditions. NASA Glenn is engaged in testing solar cells under extended temperature ranges, developing theoretical models of cell operation as a function of temperature, and in developing technology for improving the performance of solar cells for both high and low temperature operation.
\end{abstract}

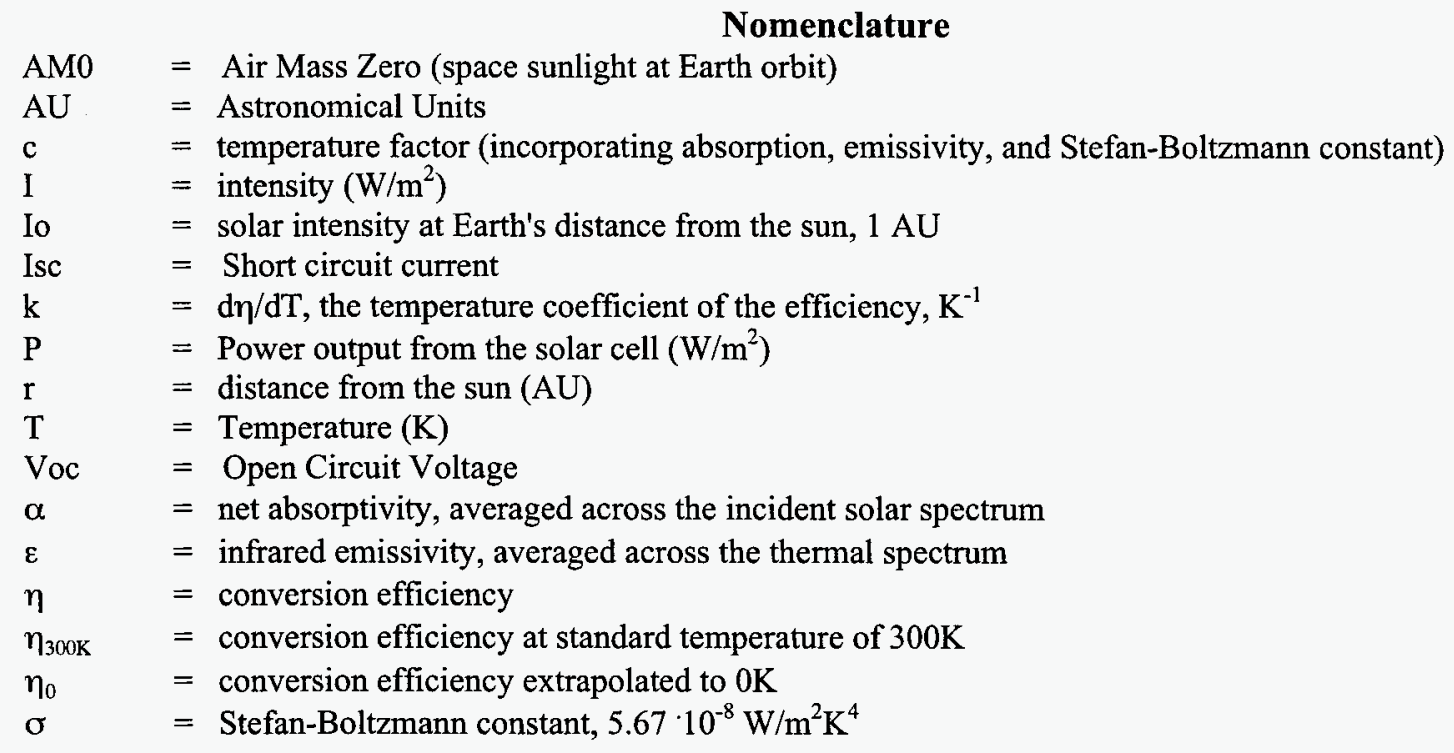

\footnotetext{
"Physicist, Photovoltaics and Space Environmental Effects, mailstop 302-1, NASA Glenn Research Center, 21000 Brookpark Road, Cleveland, OH 44135, geoffrey.a.landis@nasa.gov, AIAA Associate Fellow

${ }^{\dagger}$ Aerospace Engineer. OAI, NASA Glenn Research Center mailstop 302-1, 21000 Brookpark Road, Cleveland, OH 44135. phillip.p.jenkins@grc.nasa.gov

**Physicist; Physics Department, RIT, 85 Lomb Memorial Drive, Rochester, NY 14623. rprsps@ritvax.rit.edu
}

This is a preprint or reprint of a paper intended for presentation at a conference. Because changes may be made before formal publication, this is made available with the understanding that it will 1 not be cited or reproduced without the permissipepfath patsttuex of Aeronautics and Astronautics 


\section{Introduction}

$\mathrm{S}_{\mathrm{i}}$ olar arrays are critical to supply power for future NASA missions. Currently-available solar cells are suitable for commercial missions such as communications satellites, weather satellites, and Earth-orbiting missions, but future NASA missions will require solar array operation in extreme temperature environments, both high temperature (Mercury orbiter, Venus missions, solar probe) and low temperatures (Mars polar regions, main belt asteroids, solar-electric propulsion to outer planets) [1].

\section{Missions}

For commercial space missions, temperature is not a potential "showstopper" issue, but for NASA use, extending the temperature range of operation is critical to mission success. Achieving high-efficiency and reliable operation in these temperature regimes is a difficult technological challenge. Existing solar cells suffer significant performance loss at the high temperatures encountered in Mercury orbit and near the sun [2,3], and low temperature operation presents a separate problem that is not being addressed elsewhere on high-efficiency cells. NASA Glenn is developing methods to test solar cells for operation at temperature extremes, and attempting to develop new photovoltaic concepts for high temperature, high solar intensity missions and low-temperature, low intensity operation. Figure 1 shows a concept for a near-sun mission.

In addition to missions to regions close to the sun, such as Solar Probe [4], another possible application of hightemperature solar cells is for high-concentration sunlight. One proposed approach to reducing the cost and weight of solar arrays is to use a large area Fresnel lens to concentrate light onto a small, high-efficiency solar array. For example, figure 2 shows the "Solar Clipper," a proposal for using such a concentrator for a power source for an ionengine vehicle [5] for a Mars mission. In this proposed design, a lightweight inflatable structure holds a 15-meter diameter thin-film Fresnel lens. A similar concept has been proposed as a system to collect energy in Earth orbit to beam to the surface [6].

Unfortunately, this system is not practical for existing photovoltaic cells, since the loss of efficiency with temperature results in extremely low performance, or else thermal radiators must be employed on the photovoltaic panels to reject the waste heat. Analysis of the difficulty of thermal radiators shows that, in general, the increase in weight due to the added radiator mass more than offsets the decrease in the solar panel area. However, development of a new technology of solar arrays with reduced thermal coefficient could allow such an approach to be successful

Likewise, NASA has missions into the outer solar system, where solar cells operate at extremely low temperatures. Again, this issue is not being addressed by other projects, but is of significant interest to NASA missions. In particular, the LILT (Low Intensity, Low Temperature) operating regime was extensively tested on silicon cells, [7]. It is less well characterized for newer designs of multi-junction cells, although some recent work $[8,9,10]$ has been done. LILT effects are not a fundamental physics issue, but consist of a set of degradation mechanisms associated with carrier freeze-out and thermal barriers to conduction.

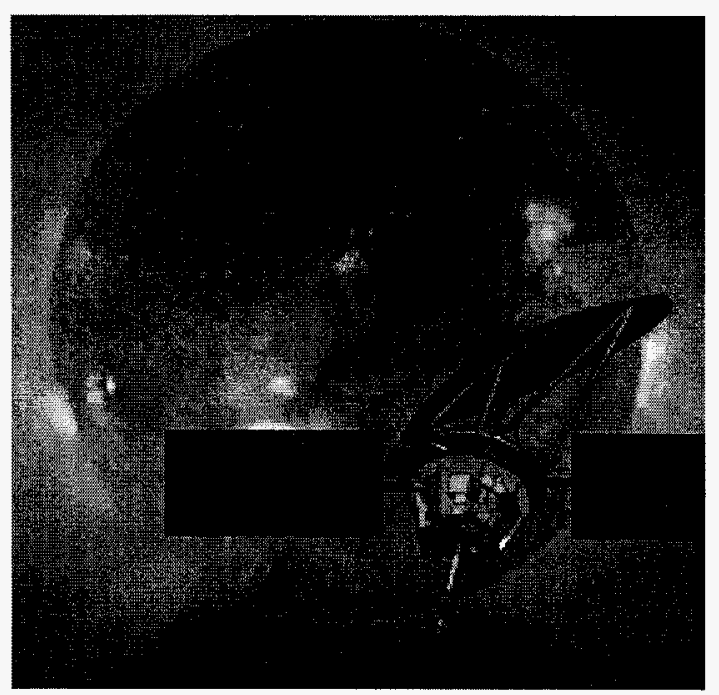

Figure 1: Artist's conception of the Solar Probe mission [4], proposed to reach a distance of 4 solar radii from the sun 


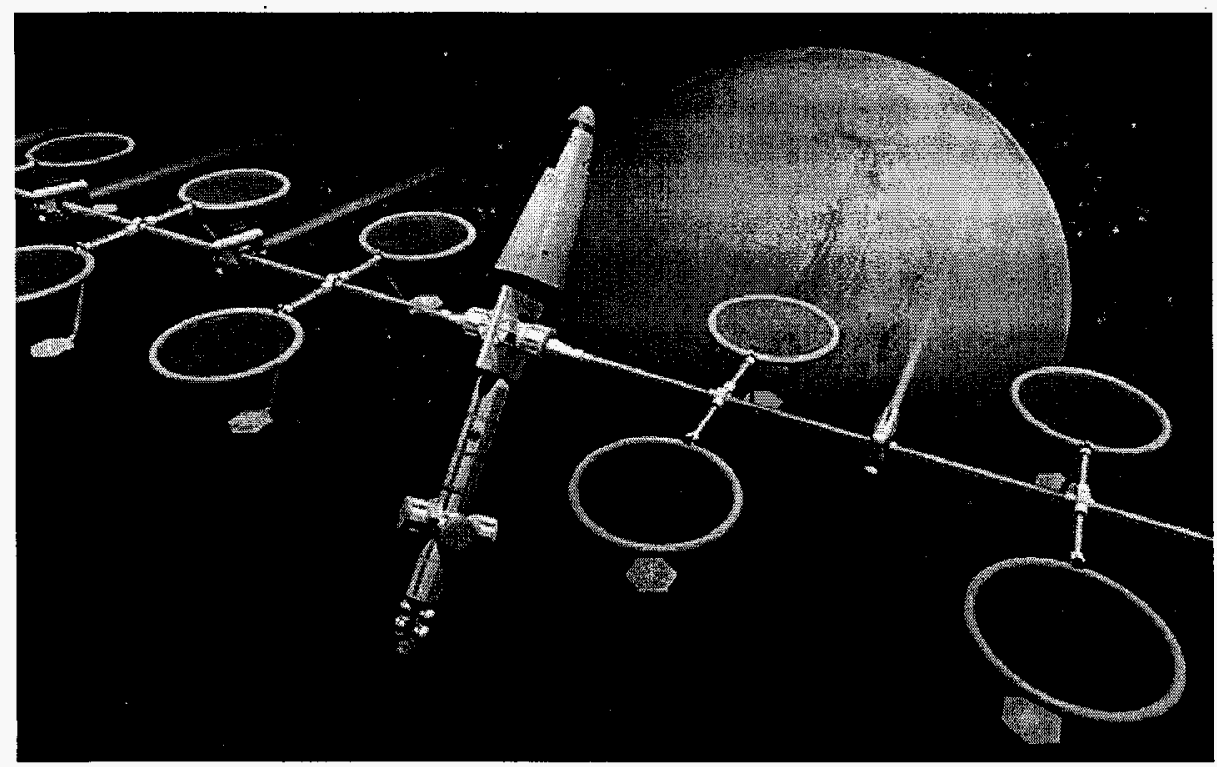

Figure 2. "Solar Clipper," a conceptual design of the use of large area, lightweight Fresnel lenses to concentrate light onto small solar arrays to provide electrical power for an ion-engined Mars vehicle (Artist's conception by Pat Rawlings for NASA).

For potential NASA missions to Mars and beyond, it will be desirable to test both existing cell types and also possible advanced designs in order to determine whether LILT degradations mechanisms are to be found in new cell designs, and what technology solutions might be used to address any such problems found. Beyond the screening of cells, it would be desirable to identify what cell design approaches could be used specifically to enhance performance under low temperature and low illumination conditions.

Finally, while missions to near-sun environments may have a high operating temperature during the actual science part of the mission (e.g., encountering the sun), the mission will still originate at Earth orbit. It would be desirable to develop cells that can operate during the full mission. Thus, an extended temperature range cell that will perform well at both high and low temperature is an ultimate goal of this program.

\section{High-Temperature Solar Cells}

\section{A. Solar Cell Operating Temperature and Efficiency}

If future missions designed to probe environments close to the sun will be able to use photovoltaic power generation, solar cells that can function at high temperatures, under high light intensity, and high radiation conditions must be developed. The significant problem is that solar cells lose performance at high temperatures.

The operating temperature of a solar cell depends on fourth root of the incident intensity, as well as the ratio of solar absorptivity alpha $(\alpha)$ to thermal emissivity epsilon $(\varepsilon)$. According to radiative balance, if $I$ is the incident intensity, the thermal radiation from the cell must equal the absorbed solar radiation:

$$
\alpha I=\left(\varepsilon_{\mathrm{f}}+\varepsilon_{\mathrm{r}}\right) \sigma \mathrm{T}^{4}
$$

where $\mathrm{T}$ is the operating temperature in absolute (Kelvin) units, and the subscripts $\mathrm{f}$ and $\mathrm{r}$ indicate the emissivity from the front and rear sides of the cell, to account for the fact that the cell can radiate waste heat away from both front and back sides $\left(\varepsilon_{\mathrm{r}}\right.$ should be left out for a cell with no back-side radiation). For convenience, here we define the absorptivity $\alpha$ as the net energy absorption, incorporating a factor of $(1-\eta)$ to account for the fact that the fraction of incident energy that is converted to electricity is not absorbed by the cell. Thus the equilibrium operating temperature $\mathrm{T}$ is

where the constant $c$ is defined as

$$
\mathrm{T}=\left[\left(\alpha /\left(\left(\varepsilon_{\mathrm{f}}+\varepsilon_{\mathrm{r}}\right) \sigma\right)\right) \mathrm{I}\right]^{1 / 4}=\mathrm{c} \mathrm{I}^{1 / 4}
$$

$$
c=\left[\alpha /\left(\left(\varepsilon_{\mathrm{f}}+\varepsilon_{\mathrm{r}}\right) \sigma\right)\right]^{1 / 4}
$$

Note that since front and back side of the cell need not have identical radiative properties in the infrared, the value of $\varepsilon$ is the average of front and back side properties.

The intensity depends on distance from the sun: 


$$
\mathrm{I}=\mathrm{I} / \mathrm{r}^{2}
$$

where Io is the solar intensity at Earth's distance from the sun, one astronomical unit (AU), and distance $r$ is measured in AU. A solar cell's (unnormalized) thermal coefficient of efficiency is defined as

$$
\mathrm{k}=\mathrm{d} \eta / \mathrm{dT}
$$

and the power at a temperature $\mathrm{T}$ can be compared to the power output from a reference temperature, typically $27 \mathrm{C}$ $(300 \mathrm{~K})$ by a linear extrapolation:

$$
\mathbf{P}=\left(\eta_{300 \mathrm{~K}}+\mathrm{k} \Delta \mathrm{T}\right) \mathrm{I}
$$

In general, the thermal coefficient is negative, corresponding to decrease in performance with increasing temperature. It is composed of separate parts corresponding to the change in short circuit current, open circuit voltage, and fill-factor of the cell. Of these, the coefficient of open-circuit voltage is typically the largest contribution [11]. The thermal coefficient is not a constant, but varies slightly with both intensity and temperature [12], however, these variations are typically small in the operational range of interest, and can be ignored in a firstlevel analysis.

From this, the power output from a cell is as a nonlinear function of the intensity. Defining $\eta_{\mathrm{o}}$ as the efficiency linearly extrapolated to $0 \mathrm{~K}$, which is calculated from the efficiency at $27 \mathrm{C}$ as

we get

$$
\eta_{\mathrm{o}}=\eta_{300 \mathrm{~K}}-300 \mathrm{k}
$$

$$
P=I\left(\eta_{0}+k T\right)=I\left(\eta_{0}+k c I^{1 / 4}\right)=I \eta_{o}+k c I^{5 / 4}
$$

Figure 3 shows the curve of power out as a function of temperature for two example cell technologies. Note that this curve is concave downward, since the thermal coefficient of efficiency $\mathrm{k}$ is generally negative. For any given solar cell technology, there exists an incident intensity above which the solar cell output decreases with increased intensity. In the linear model of equation 7 , this temperature is

$$
I_{\text {peak-output }}=\left(-\eta_{\mathrm{o}} / \mathrm{kc}\right)^{4}
$$

Since $\mathrm{k}$ is negative, and decreases in magnitude as bandgap increases, photovoltaic cells from wide bandgap materials can operate at higher intensity (and hence higher temperatures) than cells from narrow-bandgap materials.

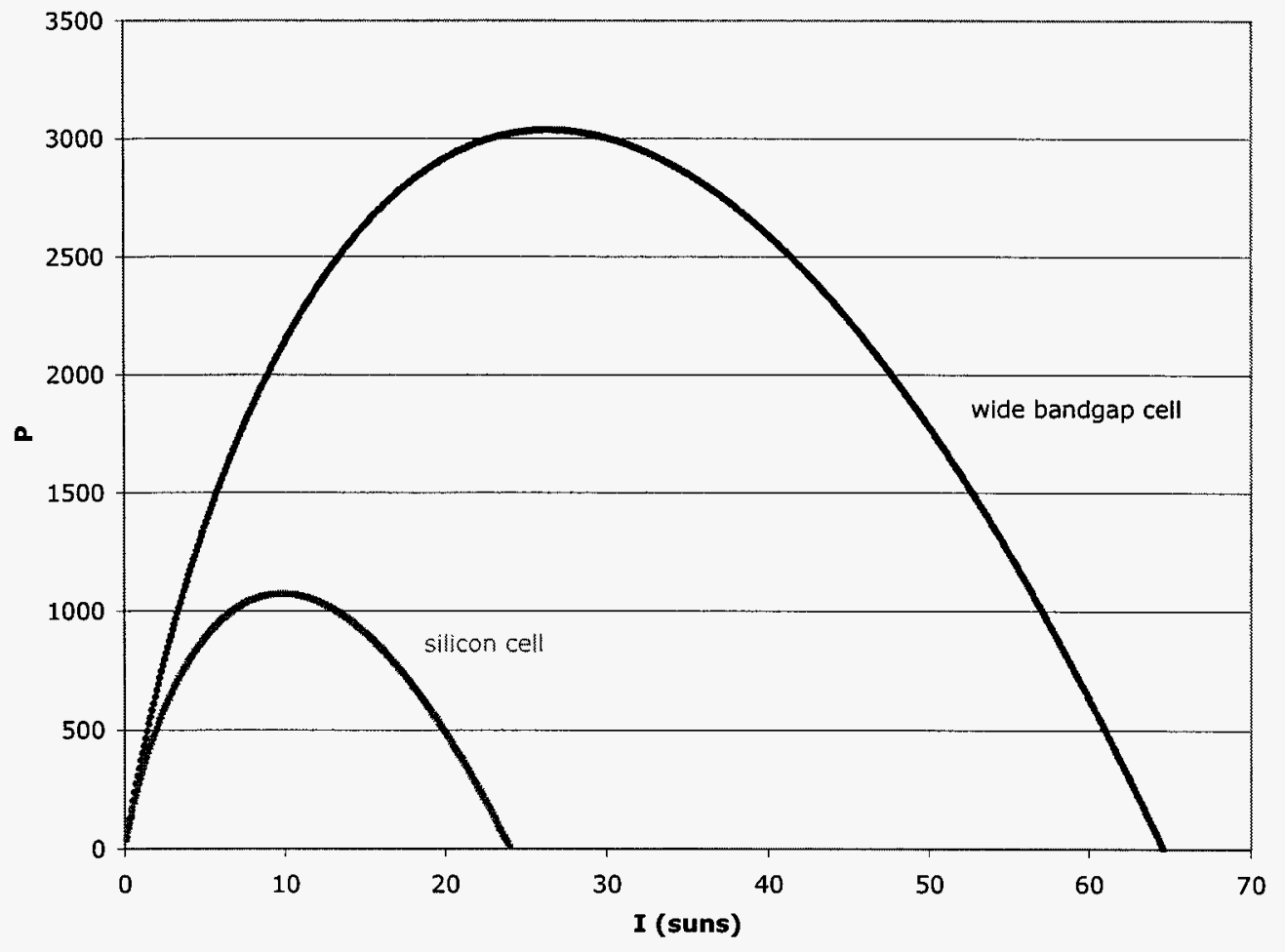

Figure 3: Curve of power output (normalized) as a function of intensity, assuming linear temperature coefficient and temperature increase as the fourth root of intensity, comparing a high-efficiency silicon solar cell with a wide-bandgap solar cell. 


\section{B. Approaches to Solar Arrays for Near Sun Missions}

Approaches to solar arrays for near-sun missions include modifying any of the terms governing temperature or efficiency of the cell: $\mathrm{I}$, the incident intensity, $\alpha$, the absorption or $\varepsilon$, the emissivity of the cell, or $k$, the temperature coefficient. Possible approaches include:

- $\quad$ High epsilon/low alpha coatings

- $\quad$ Array off-pointing: array points at angle to sun

- $\quad$ Partially-populated array (with missing cells replaced with mirrors)

- $\quad$ Spectrally-selective reflective coatings

- $\quad$ Solar cells designed to operate at high temperature (i.e., low thermal coefficient $\mathrm{k}$ )

Active cooling techniques, such as use of solid-state refrigerators, in general require more power to operate than the resultant gain in efficiency.

For example, the "MESSENGER" mission, just launched to orbit Mercury, has designed an array with mirrored panels covering $75 \%$ of the front surface of the array. This approach is used to reflect away most of the incident solar energy to limit the operating temperature and avoid destroying the array. While this is one solution to the problem, this does not optimally use the solar energy, and it would be desirable to develop solar cells that can perform well at high temperatures, rather than developing techniques to reduce the temperature at the price of reduced performance.

\section{High Temperature Solar Cell Development}

While reducing the amount of solar energy incident onto the array is one approach, it would be most desirable to manufacture cells which have high performance even at elevated temperature. Solar cells decrease in efficiency with temperature. Loss of open circuit voltage (Voc) with increasing temperature, due to increase in dark current $[2,11]$, contributes the majority of the change in efficiency. Fill factor variation in general follows the open circuit variation. A small variation of short circuit current (Isc) with temperature is primarily due to the change in bandgap energy with temperature. As the cell heats up, the bandgap decreases, and hence the cell responds to longer wavelength portions of the spectrum, and therefore the short circuit current actually increases with temperature. Hence, the Isc variation term is roughly proportional to the incident spectral intensity at wavelengths near the band edge.

Since the Voc variation with temperature is roughly the same for cells of different bandgap, while the actual Voc increases with bandgap, the normalized temperature coefficient, $1 / \eta \mathrm{d} \eta / \mathrm{dT}$ (corresponding to the fractional loss in power from the array per degree $\mathrm{K}$ ), increases directly with bandgap. From this a theoretical maximum operating temperature can be computed as a function of bandgap, where the maximum operating temperature is defined as the temperature at which the efficiency, extrapolated from the linear temperature coefficient, drops to zero.

However, since the photon flux from the sun decreases at high photon energies, an optimum bandgap exists for each temperature. Figure 4 [from ref. 3] shows this theoretical optimum bandgap as a function of temperature for two different models, one using the theoretical ideal solar-cell fill factor, and a second model assuming a maximum of 0.8 fill factor. Clearly, high bandgap materials are needed to operate at elevated operating temperatures.

Solar cells made from wide bandgap compound semiconductors are an obvious choice for such an application. In order to aid in the experimental development of high-temperature solar cells, we have initiated a program studying the theoretical and experimental photovoltaic performance of wide bandgap materials. In particular, we have been investigating the use of $\mathrm{GaP}[13], \mathrm{SiC}[14,15]$, and $\mathrm{GaN}$ materials for space solar cells.

In addition to the reversible loss of theoretical performance with temperature, solar array operation at high temperature needs to avoid irreversible degradation leading to destruction of the arrays. 


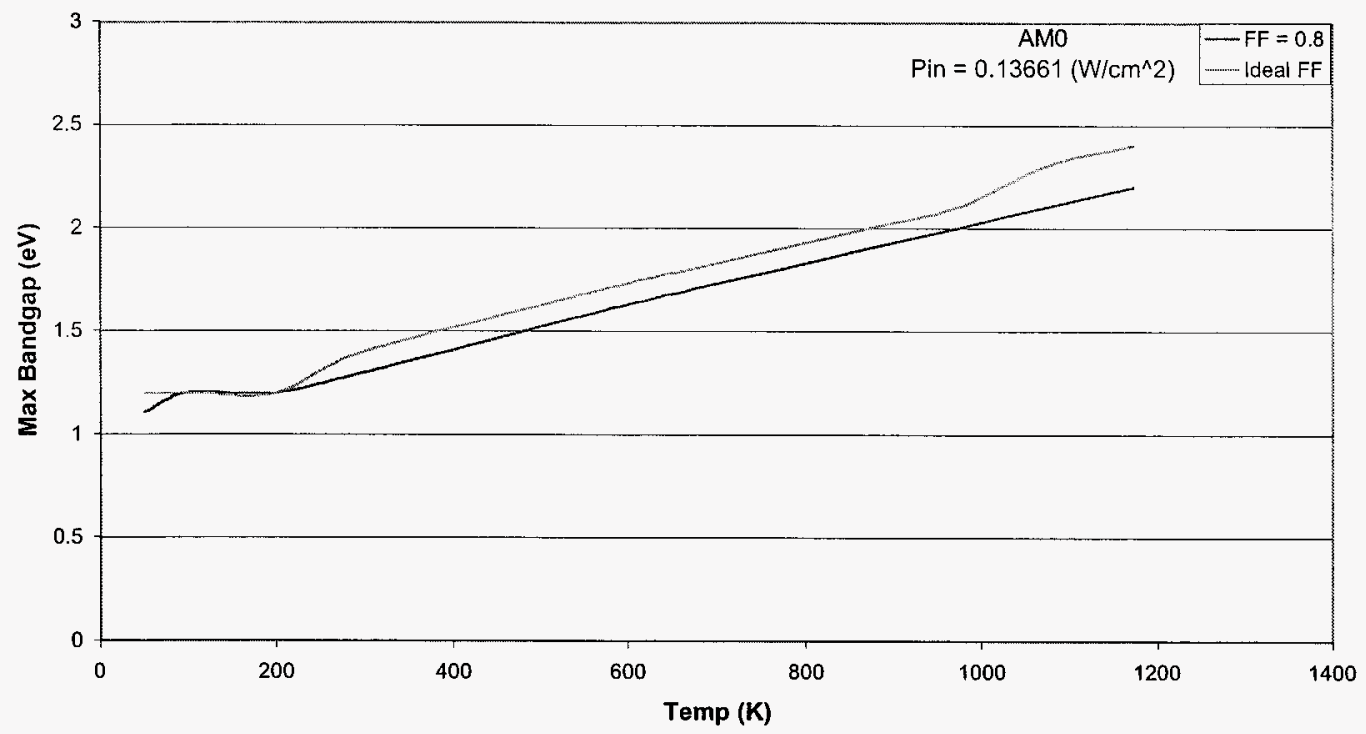

Figure 4. Theoretical optimum bandgap as a function of operating temperature, for models with fixed and variable fill-factor [3]

Effects that produce irreversible performance loss include:

- Ohmic contact degradation

- Dopant diffusion

- Compound semiconductor degradation

- Interconnect-related failure

- Coverglass debonding

- Array structural degradation.

Technologies to deal with these problems have been developed under other programs [16-17]. A major challenge with producing high temperature photovoltaics is the fabrication of contacts to the substrate material. Figure 5 shows a $\mathrm{SiC}$ solar cell fabricated are designed for use at $600{ }^{\circ} \mathrm{C}$, with $\mathrm{TiSi}_{2}$ contacts fabricated using a polysilicon deposited by chemical vapor deposition, that is stable at high temperatures.

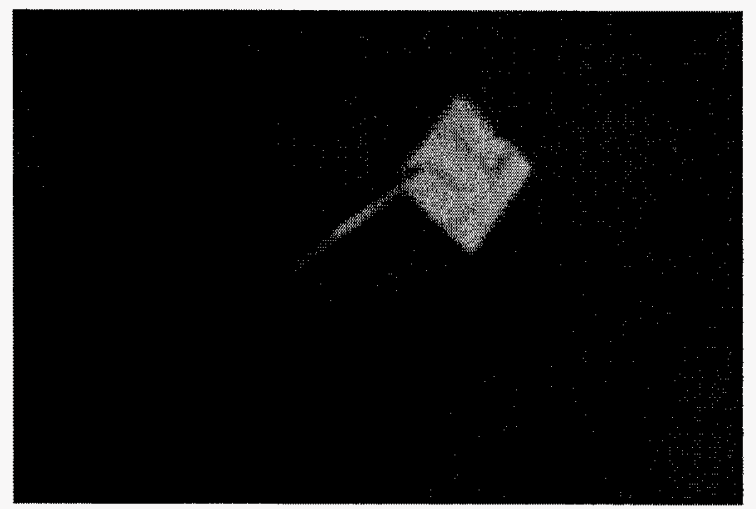

Figure 5. Digital picture showing a completed SiC solar cell with TiSi top grid contact.

\section{Conclusions}

High-temperature operation of solar cells is of interest to future NASA missions. Technology solutions such as off-pointing can reduce operating temperature, but also reduce power from the array. New solar cells that can operate at high temperature are desirable; this requires development of high bandgap semiconductors. A program to develop cells for high temperature operation, including investigation of $\mathrm{GaInP}, \mathrm{GaN}, \mathrm{SiC}$ and $\mathrm{GaP}$ cells, is in progress.

Achieving satisfactory operating lifetime at high temperature is an issue that has not yet been addressed in detail. 


\section{Acknowledgement}

The portion of the work done at the Rochester Institute of Technology was funded by NASA Grant \#NCC3-953.

\section{References}

1. G. Landis and S. Bailey, "Photovoltaic Power for Future NASA Missions," paper AIAA-2002-0718, AlAA 40th Aerospace Sciences Meeting, Reno NV, January 14-17 2002.

2. D. Scheiman, G. Landis, and V. Weizer, "High-Bandgap Solar Cells for Near-Sun Missions," Space Technology \& Applications International Forum (STAIF-99), , Albuquerque NM, 30 Jan.- 4 Feb. 1999; AIP Conference Proceedings Vol. 458, 616-620.

3. G. Landis, R. Rafaelle, and D. Merritt, "High Temperature Solar Cell Development," 19th European Photovoltaic Science \& Engineering Conference, Paris France, June 7-11 2004.

4. S. Kerridge, et al. "Cost Effective Mission Design for a Small Solar Probe," Acta Astronautica, Vol. 35, Suppl., pp. 257-266 (1995).

5. S. Oleson, "Advanced Electric Propulsion For Space Solar Power Satellites." NASA/TM-1999-209307 (paper AIAA-99-2872), 35th Joint Propulsion Conference and Exhibit, Los Angeles, California, June 20-24, 1999.

6. J. C Mankins, "A Fresh Look at Space Solar Power: New Architectures, Concepts and Technologies", IAF-97R.2.03, 38th International Astronautical Federation Congress.

7. G. Strobl and H. Fiebrich, "Production Experience with HIETA/NR-LILT Silicon Solar Cells for ROSETTA Qualification," 5th European Space Power Conference, 1998, pp. 519-522.

8. C. J. Gelderloos et al., "Low Intensity Low Temperature Performance of Advanced Solar Cells," 29th IEEE Photovoltaic Specialist's Conference, New Orleans, LA, pp. 804-907 (2002).

9. P. M. Stella, et al., "The Performance of Advanced Solar Cells for Interplanetary Missions," 28th IEEE Photovoltaic Specialist's Conference, Anchorage, AK, 2000, pp. 1354-1357.

10. P. Stella, et al., "The Environmental Performance at Low Intensity, Low Temperature (LILT) of High Efficiency Triple Junction Solar Cells," 2nd International Energy Conversion Engineering Conference, 2004.

11. J. C. C. Fan, "Theoretical Temperature Dependence of Solar Cell Parameters," Solar Cells 17, pp. 309-315 (1986).

12. C. M. Whitaker, et al., "Effects of Irradiance and Other Factors on PV Temperature Coefficients," 22nd IEEE Photovoltaic Specialist's Conference, Las Vegas NV (1991).

13. O. Sulima et al., "High Temperature AlGaP/GaP Solar Cells for NASA Space Missions," 3rd World Conference on Photovoltaic Energy Conversion, Osaka Japan, May 11-18 2003.

14. R. Raffaelle, S. Bailey, P. Neudeck, R. Okojie, C. Schanabel, M. Tabib-Azar, D. Scheiman, P. Jenkins, and S. Hubbard, "Optical and Electrical Characterization of SiC Devices, Proc. $28^{\text {th }}$ IEEE Photovoltaic Specialists Conf., pp. 1257-1260 (2000).

15. S. Bailey and R. Rafaelle, "Silicon Carbide Solar Cells Investigated," Research \& Technology 2001, NASA Technical Memorandum (2002),

16. S. P. Tobin et al. "Advanced Metallization for Highly Efficient Solar Cells," Proc. 19th IEEE Photovoltaic Specialists Conf., pp. 70-75 (1987).

17. M. B Spitzer., et al. "Gallium Arsenide Concentrator Solar Cells with Highly Stable Metallization," Proc. 20th IEEE Photovoltaic Specialists Conference, pp. 930-933 (1988). 